\title{
VIETNAM - AFRICA ECONOMIC AND TRADE RELATIONS IN RECENT YEARS
}

Nguyen Khanh Nhu

$T N U$ - University of Education

\begin{tabular}{|c|c|c|}
\hline \multicolumn{2}{|c|}{ ARTICLE INFO } & ABSTRACT \\
\hline Received: & $21 / 10 / 2021$ & This study is implemented to understand the economic and trade \\
\hline Revised: & 18/11/2021 & $\begin{array}{l}\text { relations between Vietnam and Africa in recent years. The economic- } \\
\text { trade relationship between Vietnam and Africa is of particular interest }\end{array}$ \\
\hline Published: & $18 / 11 / 2021$ & to academia and researchers due to the strong acceleration in bilateral \\
\hline & & trade turnover, reaching new heights. Africa is a potential market for \\
\hline \multicolumn{2}{|l|}{ KEYWORDS } & Vietnamese commodity exporters. studying economic and trade \\
\hline \multicolumn{2}{|l|}{ Vietnam } & good solution for bilateral trade cooperation, helping Vietnam to \\
\hline \multicolumn{2}{|l|}{ Africa } & expand into new markets, avoiding dependence on some previous \\
\hline \multicolumn{2}{|l|}{ Economic } & traditional markets before. Based on data sources in the fields of \\
\hline \multicolumn{2}{|l|}{ Trade } & $\begin{array}{l}\text { diplomacy, economic cooperation, culture and bilateral trade, the study } \\
\text { has summarized, generalized and given general comments, assessment }\end{array}$ \\
\hline \multicolumn{2}{|l|}{ Relations } & $\begin{array}{l}\text { of difficulties and limitations. At the same time, this study proposed } \\
\text { appropriate countermeasures and solutions for the development of } \\
\text { economic and trade cooperation between Vietnam and African } \\
\text { countries, recommending countermeasures to promote bilateral } \\
\text { cooperation in the current period. }\end{array}$ \\
\hline
\end{tabular}

\section{QUAN Hệ KINH TẾ THƯƠNG MẠI VIẸTT NAM - CHÂU PHI TRONG NHUỦNG NĂM GẦN ĐÂY}

\section{Nguyễn Khánh Như}

Truò̀ng Đại học Su phạm - ĐH Thái Nguyên

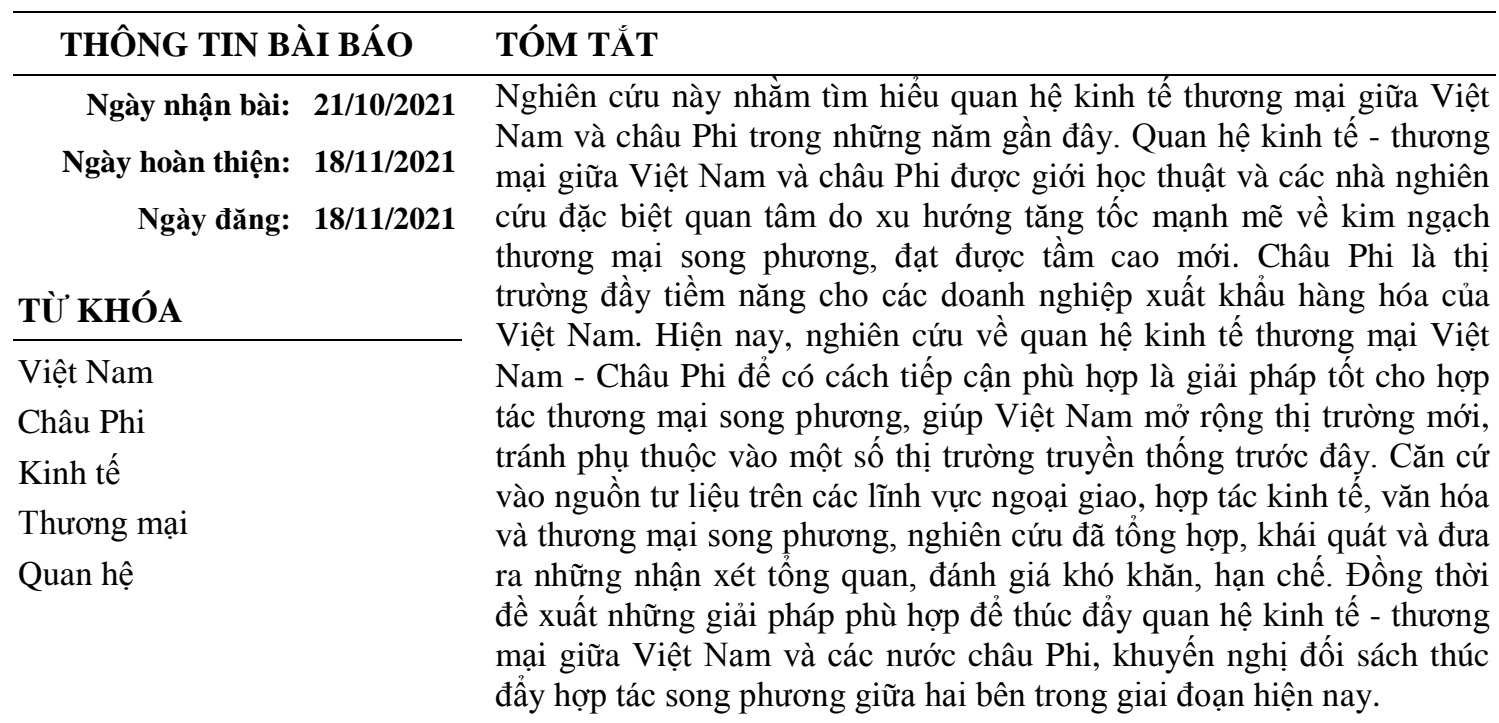

DOI: $\underline{\text { https://doi.org/10.34238/tnu-jst.5189 }}$

Email:nhunk@tnue.edu.vn 


\section{Giới thiệu}

Việt Nam là một trong những quốc gia có triển vọng về phát triển kinh tế ở Đông Nam Á, là thành viên của N-11 - Next Eleven - 11 nền kinh tế lớn tiếp theo và VISTA (viết tắt cho các nền kinh tế như Vietnam, Indonesia, South Africa, Turkey, Argentina - được dùng ở lĩnh vực kinh tế trong việc thảo luận thị trường mới nổi). Chi phí nhân lực ở Việt Nam tương đối thấp, chính sách cởi mở ổn định, lao động trẻ chiếm số lượng đông đảo và môi trường đầu tư tương đối thuận lợi khiến cho Việt Nam trở thành quốc gia Đông Nam Á có tiềm năng tăng trưởng kinh tế mạnh mẽ. Kể từ sau đổi mới và mở cửa năm 1986, Việt Nam đã đạt được nhiều thành tựu to lớn trong xây dựng kinh tế, bình thường hóa quan hệ với Hoa Kỳ, gia nhập Tổ chức Thương mại Thế giới, tích cực hoạt động trong ASEAN, có ảnh hưởng tại các tổ chức khu vực và quốc tế.

Sự phát triển của châu Phi trong những năm gần đây cũng đáng được toàn cầu quan tâm. Quan hệ đối tác chiến lược với châu Phi được nhiều quốc gia chú trọng và nâng cấp thành quan hệ đối tác hợp tác chiến lược toàn diện, trong đó có Việt Nam [1].

Trong những năm qua, xuất khẩu hàng hóa của Việt Nam sang thị trường châu Phi có nhiều khởi sắc, với tổng kim ngạch xuất khẩu các mặt hàng nông sản, thủy sản đạt 1774,9 triệu USD năm 2018 [2]. Tận dụng cơ hội về nhu cầu nhập khẩu nhiều loại mặt hàng lương thực, thực phẩm với số lượng lớn của các quốc gia ở châu Phi, Việt Nam từng bước mở rộng được thị trường xuất khẩu các mặt hàng có ưu thế sang châu lục nhiều tiềm năng này. Cơ cấu kinh tế thương mại song phương chủ yếu là các mặt hàng nông sản, dệt may và một tỷ trọng nhỏ là máy móc hạng nặng. Theo số liệu thống kê từ Tổng cục Hải quan Việt Nam năm 2018, xuất khẩu nông sản, thủy sản sang châu Phi đạt 829,2 triệu USD, tăng 2,82\% so với năm 2017 (cao hơn tốc độ tăng bình quân cả giai đoạn 2014-2018 ở mức 0,23\%) [2].

Trong bối cảnh Việt Nam đang tích cực tham gia hội nhập kinh tế quốc tế, thương mại ngày càng đóng vai trò quan trọng trong sự phát triển kinh tế xã hội của đất nước. Việt Nam đã có những nỗ lực đáng kể nhằm giảm chi phí thương mại và thời gian để tạo thuận lợi cho các hoạt động thương mại [3].

Châu Phi cũng là một thị trường phát triển công nghệ đầy tiềm năng với vị trí là lục địa đông dân thứ hai trên thế giới cũng như tình hình tăng trưởng kinh tế nhanh chóng. Từ những năm 1980, nhiều nước đang phát triển ở Châu Phi bắt đầu tái cơ cấu nền kinh tế và mở cửa hướng tới thị trường toàn cầu, một phần sau khi tiếp nhận lý thuyết kinh tế tân tự do cầm quyền. Tuy nhiên, kết quả của các quá trình này hầu như không rõ ràng, đặc biệt là về các hậu quả xã hội. Các quốc gia Bắc Phi, Maroc, Tunisia và Ai Cập cũng không ngoại lệ. Được kết nối mạnh mẽ với nền kinh tế EU, các quốc gia này đã ký các hiệp định thương mại tự do để tạo khả năng tiếp cận tốt hơn với Thị trường chung châu Âu, nhưng họ cũng đang mở cửa cho nền kinh tế của mình trước sự cạnh tranh ngày càng tăng [4].

Số người sử dụng Internet trên thế giới tăng 1,239\% tính từ năm 2000 cho đến tháng 7 năm 2020, thì ở châu Phi số người sử dụng Internet bùng nổ với 12,441\% - gấp hơn 10 lần tốc độ tăng trưởng của thế giới. Trong đó Nam Phi là một trong các nước có tốc độ phát triển thương mại điện tử (TMĐT) đứng đầu, các trang web TMĐT ở Nam Phi cũng đã trở thành điểm đến phổ biến cho người mua sắm từ các quốc gia khác ở châu Phi, đặc biệt là Nigeria và $\mathrm{Ai}$ Cập [5].

Nam Phi cũng là quốc gia chiếm $88 \%$ trữ lượng platin, $72 \%$ trữ lượng crôm, $80 \%$ trữ lượng măng-gan, $30 \%$ trữ lượng titan, $44 \%$ trữ lượng vanadi... của thế giới [6].

Theo báo cáo của Thông tấn xã Việt Nam, Nam Phi vẫn là đối tác thương mại lớn nhất của Việt Nam tại châu Phi trong năm 2018, với kim ngạch thương mại xuất nhập khẩu đạt 1,1 tỷ USD, tăng $11,7 \%$ so với năm 2017 và chiếm $16 \%$ tổng kim ngạch thương mại của Việt Nam với châu Phi [7].

Quan hệ Việt Nam- Ai Cập đã trải qua một chặng đường lịch sử khá lâu dài. Ai Cập là nước Arập đầu tiên thiết đặt quan hệ ngoại giao chính thức với Việt Nam. Điều này chứng tỏ tình cảm, thiện ý cũng như tầm nhìn ngoại giao của nước cộng hòa Hồi giáo này đối với Việt Nam [8]. 
Các hoạt động ngoại giao kinh tế và thương mại cấp cao gần đây của Việt Nam với châu Phi liên tục diễn ra. Có thể kể tới là chuyến thăm của nguyên Chủ tịch nước Trần Đại Quang đã đến thăm Ai Cập và Ethiopia tháng 8 năm 2018 [9]; buổi tiếp của nguyên Chủ tịch nước Trần Đại Quang với Bộ trưởng Bộ Ngoại giao Rwanda Louise Mushikiwabo và Bộ trưởng Bộ Ngoại giao Guinea Mamadi Toure vào tháng 8 năm 2018 [10]; chuyến thăm của Thứ trưởng Ngoại giao Nguyễn Quốc Cường đến Ai Cập vào tháng 3 năm 2019...[11].

Trong một thời gian dài, Việt Nam đã tập trung tăng cường quan hệ ngoại giao với các nước lớn ở Châu Á - Thái Bình Dương như: Hoa Kỳ, Trung Quốc, Nhật Bản, Hàn Quốc và nước Đông Nam Á, trong khi đó châu Phi lại rất mờ nhạt. Tuy nhiên, trong những năm gần đây, quan hệ kinh tế thương mại, giao lưu chính trị, giao lưu văn hóa giữa Việt Nam và châu Phi ngày càng rộng mở. Do đó, nghiên cứu về quan hệ Việt Nam - châu Phi, đặc biệt là quan hệ kinh tế - thương mại sẽ giúp chúng ta nhìn nhận rõ chính sách đối ngoại của Việt Nam trong bối cảnh quan hệ quốc tế mới và hiểu được xu hướng mới trong hoạt động ngoại giao của Việt Nam.

Nghiên cứu về châu Phi, tạo điều kiện cho các hoạt động trao đổi thương mại, hoàn thiện khuôn khổ pháp lý, cơ chế chính sách đầu tư... là vấn đề cần thiết, cấp bách trong giai đoạn hiện nay. Mặc dù đã có một số công trình nghiên cứu đề cập đến quan hệ thương mại song phương Việt Nam - Châu Phi. Tuy vậy, để có cái nhìn tổng quan, sâu sắc và đề xuất được những giải pháp cụ thể hơn nữa, tạo ra môi trường đầu tư thông thoáng cho doanh nghiệp đôi bên hợp tác phát triển, chúng ta cần có những nghiên cứu rộng và sâu hơn nữa về hợp tác toàn diện Việt Nam - Châu Phi.

\section{Phương pháp nghiên cứu}

\subsection{Bối cảnh nghiên cứu}

Trong những năm gần đây, châu Phi dần nổi lên như một khu vực phát triển năng động trên thế giới. Quan hệ đối tác chiến lược với châu Phi được nhiều quốc gia chú trọng và nâng cấp thành quan hệ đối tác chiến lược toàn diện. Việt Nam và nhiều nước châu Phi thiết lập quan hệ hữu nghị truyền thống từ khá sớm. Mặc dù tiềm năng hợp tác đầu tư kinh tế thương mại song phương chưa được khai thác hết trong những năm gần đây, nhưng kim ngạch thương mại song phương tiếp tục tăng trưởng, bề rộng và chiều sâu của hợp tác kinh tế thương mại đã được cải thiện đáng kể.

\section{2. Đối tuọng nghiên cứu}

Những năm gần đây, nhiều doanh nghiệp Việt Nam coi châu Phi là thị trường, đối tác tiềm năng và tích cực đầu tư vào các nước châu Phi. Nghiên cứu về quan hệ hợp tác kinh tế, thương mại giữa Việt Nam và các nước châu Phi sẽ góp phần rút ra những bài học kinh nghiệm cho mỗi quốc gia trong quá trình hội nhập, phát triển đất nước. Các lĩnh vực kinh tế của châu Phi mà Việt Nam chú trọng nghiên cứu thị trường, tăng cường đầu tư, hợp tác có thể kể tới là: trồng lúa, nuôi trồng thủy sản, trồng và chế biến cà phê, chế biến nông sản và khai thác khoáng sản.

\subsection{Phương pháp thu thập và xử lí số liệu}

Nghiên cứu này được thực hiện trên cơ sở phân tích, tổng hợp và xử lí nguồn tư liệu là các công trình, bài báo đã xuất bản, luận văn, đề tài khoa học các cấp đã nghiệm thu và nguồn tư liệu từ cổng thông tin online chính thống của Thông tấn xã Việt Nam. Ngoài ra, tác giả còn sử dụng cách tiếp cận nghiên cứu dựa trên quan điểm của những nhà nghiên cứu châu Phi tại Việt Nam.

\section{Kết quả và thảo luận}

\subsection{Kết quả}

Việt Nam và nhiều nước châu Phi thiết lập quan hệ hữu nghị truyền thống từ khá sớm. Mặc dù tiềm năng hợp tác đầu tư kinh tế thương mại song phương chưa được khai thác hết trong những 
năm gần đây, nhưng kim ngạch thương mại song phương tiếp tục tăng trưởng, bề rộng và chiều sâu của hợp tác kinh tế thương mại đã được cải thiện đáng kể. Hiện nay, Việt Nam có quan hệ kinh tế thương mại với tất cả các nước châu Phi, trừ Nam Sudan và Eritrea. Các đối tác thương mại chính là Nam Phi ở Nam Phi; Ai Cập và Algeria ở Bắc Phi; Ghana, Bờ Biển Ngà (Côte d'Ivoire), Togo và Nigeria ở Tây Phi. Việt Nam xuất khẩu điện thoại di động, linh kiện máy tính và sản phẩm dệt may, giày dép, gạo, cà phê, hạt tiêu, dừa, hạt điều, cá tra, tôm, vật liệu xây dựng và các mặt hàng khác sang châu Phi. Nông sản, thủy sản và vật liệu xây dựng của Việt Nam dần có chỗ đứng trên thị trường châu Phi.

Trong những năm gần đây, châu Phi dần nổi lên như một khu vực phát triển năng động trên thế giới. Các nước châu Phi rất coi trọng những thành tựu phát triển kinh tế của Việt Nam, đặc biệt trong lĩnh vực kinh tế nông nghiệp như trồng lúa, nuôi trồng thủy sản, trồng và chế biến cà phê. Các ngành sản xuất gạo, dệt may, chế tạo giày dép, máy móc, sản phẩm nhựa, sản phẩm gỗ, xe máy, xe đạp và điện tử của Việt Nam là những ngành có thế mạnh của Việt Nam tại thị trường các nước châu Phi. Những năm gần đây, Việt Nam cũng đã tăng cường mối quan hệ hợp tác kinh tế với nhiều quốc gia châu Phi. Năm 2014, Việt Nam đã ký hiệp định hợp tác thương mại với 25 nước châu Phi, đến năm 2017 đã thiết lập quan hệ thương mại với tất cả các nước châu Phi. Việt Nam xây dựng chiến lược thúc đẩy xuất khẩu sang thị trường châu Phi, bao gồm tăng cường các hoạt động xúc tiến thương mại, hỗ trợ các công ty Việt Nam quảng bá thông tin sản phẩm đến khách hàng, tham gia các hội chợ thương mại và hội thảo doanh nghiệp...

Năm 2010, "Diễn đàn doanh nghiệp Việt Nam - Châu Phi" lần thứ hai được tổ chức tại Hà Nội, thu hút hơn 150 đại biểu là các DN Việt Nam và châu Phi cùng tham dự. Theo Phó Chủ tịch Phòng Thương mại và Công nghiệp Việt Nam (VCCI) Đoàn Duy Khương, mối quan hệ hợp tác Việt Nam- châu Phi đang có những bước phát triển nhanh chóng cả trong lĩnh vực chính trị lẫn kinh tế. Các doanh nghiệp Việt Nam có thế mạnh trong lĩnh vực nông nghiệp, chuyển giao khoa học- công nghệ trong nông nghiệp, là những lĩnh vực mà các doanh nghiệp châu Phi đang rất mong muốn được hợp tác và đầu tư. Phía châu Phi hy vọng "Diễn đàn doanh nghiệp Việt Nam Châu Phi" sẽ tạo thành cơ chế đối thoại thường xuyên, có lợi cho doanh nghiệp, xây dựng nền tảng tăng cường và củng cố quan hệ thương mại và đầu tư song phương. Châu Phi hiện là thị trường có nhu cầu nhập khẩu nông sản lớn, đặc biệt khu vực Tây Phi có nhu cầu tiêu thụ gạo lớn do sản xuất lúa không đủ. Ghana và Cote d'Ivoire là các thị trường nhập khẩu nông sản, thủy sản; Algeria nhập khẩu hạt tiêu, chè, cà phê, gia vị, thịt, gạo, ngũ cốc...; Nam Phi nhập khẩu nông sản, gia vị... từ Việt Nam [12].

Có thể thấy, châu Phi là một trong những thị trường phát triển nhanh nhất trong chiến lược thương mại của Việt Nam những năm gần đây và được đánh giá là thị trường thương mại và đầu tư có tiềm năng rất lớn tại Việt Nam. Các nước châu Phi kêu gọi các công ty Việt Nam đầu tư và chuyển giao công nghệ. Đầu tư vào Châu Phi không chỉ tận dụng được nhiều nguồn nguyên liệu thô, lao động địa phương và người tiêu dùng mà còn được hưởng thuế suất ưu đãi khi xuất khẩu sang khu vực này.

Bên cạnh những thuận lợi, châu Phi với đặc điểm chính trị phức tạp, bất ổn, kèm theo đó là hàng loạt rào cản thương mại ảnh hưởng không nhỏ đến hợp tác song phương. Sự phân bố thương mại và đầu tư theo khu vực giữa Việt Nam và các nước Châu Phi không đồng đều. Tính đến năm 2015, Việt Nam đã đầu tư vào 33 dự án tại 12 quốc gia ở châu Phi, các điểm đến đầu tư là Algeria, Tanzania, Mozambique, Cameroon, Burundi và một số nước khác; mục đích đầu tư liên quan đến thăm dò dầu khí, viễn thông, thủy điện, chế biến gỗ và các lĩnh vực khác với vốn đầu tư khoảng 2,597 tỷ USD [3]. Theo số liệu thống kê của Cục Đầu tư nước ngoài, tính đến tháng 8/2018, 16 quốc gia và khu vực châu Phi đã đầu tư vào Việt Nam 247 dự án, với tổng giá trị 1,562 tỷ USD [3]. Seychelles, Mauritius, Angola và Swaziland là những quốc gia đầu tư nhiều nhất vào Việt Nam. Lĩnh vực đầu tư chủ yếu là chế biến, chế tạo, bán lẻ, sửa chữa và công nghệ. Các nước châu Phi có hệ số rủi ro cao dù 43 quốc gia châu Phi đã gia nhập Tổ chức Thương mại Thế giới và đang từng bước dỡ bỏ các hàng rào phi thuế quan, giảm thuế nhập khẩu. Ví dụ, nhà 
đầu tư cần phải tuân thủ nhiều quy định và tiêu chuẩn của các nước châu Phi, bao gồm nhãn hiệu, chỉ số và thông tin liên quan của sản phẩm xuất khẩu phải được đánh dấu bằng tiếng $\mathrm{Anh}$, tiếng Pháp và ngôn ngữ của quốc gia đặt trụ sở. Ngoài ra, do khoảng cách giữa hai bên còn xa, phương thức giải quyết vấn đề phát sinh trong thương mại song phương khó khăn đã cản trở các công ty Việt Nam thâm nhập thị trường châu Phi. Các đại diện ngoại giao và tổ chức thương mại của Việt Nam tại các nước châu Phi còn hạn chế về số lượng, tình trạng gian lận thương mại ở một số quốc gia phía tây châu Phi vẫn thường xuyên xảy ra. Ngoài ra, môi trường thương mại song phương giữa Việt Nam và châu Phi còn chịu sức ép cạnh tranh từ các nước khác như Malaysia, Trung Quốc, Ân Độ và Thái Lan. Bên cạnh đó, những bất ổn về chính trị - xã hội ở một số nước châu Phi, khác biệt về ngôn ngữ, văn hóa, hệ thống luật pháp, thói quen kinh doanh, điều chỉnh đi lại giữa hai bên đều ảnh hưởng không nhỏ đến quá trình hợp tác song phương.

Quan hệ kinh tế thương mại giữa Việt Nam với một số nước châu Phi tiêu biểu có thể kể đến trong những năm gần đây là: Nam Phi, Tây Phi, Ai Cập, Bắc Phi...

Quan hệ kinh tế thương mại với khu vực Nam Phi: Trong nửa sau của thế kỷ 20, Việt Nam tích cực ủng hộ nhiều chính sách phát triển kinh tế của Nam Phi, Mozambique và Angola. Sự ra đời của Cộng đồng Phát triển miền Nam châu Phi (SADC) năm 1992 đã trở thành nền tảng quan trọng thúc đẩy hợp tác kinh tế và thương mại ở Nam Phi. Mối quan hệ chặt chẽ giữa Việt Nam và SADC chính là tiềm năng lớn cho việc tăng cường hợp tác về thương mại, đầu tư, du lịch và kỹ thuật. Tháng 8/2018, Hội Hữu nghị Việt Nam - Châu Phi và Đại sứ quán các nước Nam Phi phối hợp tổ chức tọa đàm doanh nghiệp vừa và nhỏ tại Hà Nội. Các doanh nghiệp vừa và nhỏ đóng vai trò là cầu nối kinh tế thương mại giữa hai bên. Đại sứ Nam Phi tại Việt Nam Mpetjane Kgaogelo cũng cho rằng, tiềm năng của Nam Phi là rất lớn nhưng vẫn chưa được khai thác hết, Việt Nam có nhiểu kinh nghiệm trong phát triển doanh nghiệp vừa và nhỏ, phát triển kinh tế cá thể, có thể hỗ trợ các nước trong Cộng đồng phát triển Nam Phi cùng học hỏi. Nam Phi luôn là thị trường lớn nhất cho hàng hóa xuất khẩu của Việt Nam. Theo thông tin từ Vụ Thị trường Châu Á và Châu Phi của Bộ Công Thương Việt Nam, xuất khẩu của Việt Nam sang châu Phi năm 2018 lên tới gần 3 tỷ đô la Mỹ, trong đó hơn 720 triệu USD xuất sang Nam Phi, giảm nhẹ 3,6\% so với năm 2017 [5].

Quan hệ kinh tế và thương mại với khu vực Bắc Phi: Ai Cập là thị trường xuất khẩu lớn thứ hai của Việt Nam sang châu Phi. Quan hệ hợp tác kinh tế là mục tiêu hai nước đặt ra để phấn đấu thực hiện từ thập niên đầu của thế kỷ XXI cũng mới chỉ bắt đầu phôi thai khi giá trị kim ngạch trao đổi thương mại đến tận năm 2010 và 2011 vẫn chưa đạt đến con số 200 triệu USD [6]. Ai Cập tuyên bố đang theo đuổi con đường dân chủ trong cả hai cuộc bầu cử là bầu cử nghị viện và bầu cử tổng thống. Tuy nhiên, Ai Cập vẫn đang phải đối mặt với muôn vàn khó khăn, trong đó nổi bật là sự bất ổn về chính trị, xã hội và sự giảm sút về kinh tế. Năm 2018, xuất khẩu của Việt Nam sang nước này là 439 triệu USD, tăng 36,6\% so với năm 2017. Để giảm lượng nước tiêu thụ, Ai Cập đã giảm diện tích trồng lúa. Tháng 8 năm 2018, trong chuyến thăm Ai Cập của nguyên Chủ tịch nước Việt Nam Trần Đại Quang, hai bên đã đạt được thỏa thuận nhập khẩu 1 triệu tấn gạo từ Việt Nam và giao theo lô trong vòng 3-4 tháng để làm nguồn dự trữ ngũ cốc của Ai Cập. Các quan chức Ai Cập không tiết lộ giá cụ thể, chỉ nhấn mạnh rằng mức giá của Việt Nam cạnh tranh hơn giá gạo nhập từ Trung Quốc khá nhiều.

Quan hệ kinh tế và thương mại với Tây Phi: Tây Phi là đối tác thương mại quan trọng của Việt Nam tại châu Phi. Năm 2018, trong số các quốc gia đối tác xuất khẩu của Việt Nam tại châu Phi (7 ngành xuất khẩu vượt 100 triệu USD) thì có 4 nước Tây Phi là Ghana, Côte d'Ivoire, Togo và Nigeria. Ghana đứng thứ ba về thị trường xuất khẩu của Việt Nam sang châu Phi, chỉ đứng sau Nam Phi và Ai Cập, với kim ngạch xuất khẩu đạt 278,3 triệu USD, tăng 3,7\% so với năm 2017 [5].

Các hoạt động ngoại giao kinh tế và thương mại cấp cao gần đây của Việt Nam với châu Phi có thể kể tới là: chuyến thăm của nguyên Chủ tịch nước Trần Đại Quang đã đến thăm Ai Cập và Ethiopia tháng 8 năm 2018. Chuyến thăm Ethiopia là chuyến thăm đầu tiên của nguyên thủ quốc gia Việt Nam kể từ khi hai nước thiết lập quan hệ ngoại giao, là dấu mốc quan trọng trong lịch sử quan hệ song phương, đồng thời ra Tuyên bố chung, mở ra cánh cửa hợp tác đầu tư, thương mại 
giữa hai nước. Cũng trong tháng 8 năm 2018, Đại sứ đặc mệnh toàn quyền Maroc tại Việt Nam Azzeddine Farhane cho biết Maroc sẽ tập trung củng cố quan hệ kinh tế giữa hai nước và thúc đẩy phát triển thương mại song phương. Tháng 3 năm 2019, Thứ trưởng Ngoại giao Nguyễn Quốc Cường thăm Ai Cập. Thứ trưởng Ngoại giao Ai Cập Khaled Tharwat nhấn mạnh rằng Việt Nam chiếm vị trí trung tâm trong chính sách "hướng Đông" của Ai Cập. Ai Cập đánh giá cao những thành tựu phát triển kinh tế, xã hội của Việt Nam và vị thế, vai trò của Việt Nam trên thế giới và khu vực. Trên cơ sở quan hệ hữu nghị truyền thống, Ai Cập mong muốn thúc đẩy phát triển thực chất trên các lĩnh vực, trong đó có thương mại và đầu tư với Việt Nam. Vào tháng 4 năm 2019, khi tháp tùng Thủ tướng Nguyễn Xuân Phúc tới Bắc Kinh tham dự Diễn đàn Cấp cao hợp tác quốc tế "Vành đai và Con đường" lần thứ hai, Phó Thủ tướng - Bộ trưởng Ngoại giao Phạm Bình Minh đã gặp Giám đốc Văn phòng Tổng thống Liberia là Mc Clain. Ông Mc Clain mong muốn các công ty Việt Nam tăng cường đầu tư vào Liberia, đồng thời mong chính phủ và các công ty Việt Nam chia sẻ kinh nghiệm thành công trong canh tác và sản xuất lúa gạo của Việt Nam [13]. Tháng 8 năm 2019, Thủ tướng Nguyễn Xuân Phúc tiếp Bộ trưởng Ngoại giao và Hợp tác Botswana, đề nghị hai bên tăng cường hợp tác trong khuôn khổ pháp lý về kinh tế, thương mại và đầu tư; tăng cường quan hệ hợp tác giữa Việt Nam và Liên minh châu Phi, củng cố mối quan hệ giữa Việt Nam và Cộng đồng Phát triển Nam Phi (SADC). Phía Việt Nam cũng cho biết sẵn sàng thiết lập vai trò cầu nối để Botswana mở rộng hợp tác với các nước ASEAN [14]. Tháng 12 năm 2019, Bộ Ngoại giao Việt Nam và Tổ chức Pháp ngữ Quốc tế (OIF) tổ chức hội thảo "Hợp tác Việt Nam và châu Phi: Đối phó với rủi ro khi hợp tác kinh tế với các nước châu Phi" tại Hà Nội. Hội thảo đã nêu rõ Châu Phi trở thành đối tác tiềm năng của các nhà đầu tư Việt Nam, trong đó nổi bật là dự án viễn thông Viettel với tổng vốn đầu tư 1 tỷ USD. Mô hình hợp tác giữa Việt Nam và một số nước châu Phi, đặc biệt trong lĩnh vực nông nghiệp, từng được coi là hình mẫu cho hợp tác Việt Nam - Nam Phi [15]. Tháng 12 năm 2019, trong chuyến thăm và làm việc tại Ai Cập, ông Phạm Minh Chính - Ủy viên Bộ Chính trị Trung ương Đảng Cộng sản Việt Nam đã đề nghị hai bên tiếp tục tăng cường các chuyến thăm các cấp và ủng hộ lẫn nhau trên các diễn đàn quốc tế và khu vực; đề nghị $\mathrm{Ai}$ Cập tiếp tục ủng hộ Việt Nam và Liên minh châu Phi $(\mathrm{AU})$ thiết lập quan hệ chính thức. Hai bên đã thảo luận về tính khả thi của việc mở đường bay thẳng; nghiên cứu tạo điều kiện thuận lợi thúc đẩy hợp tác kinh tế, thương mại, đầu tư, văn hóa, du lịch, giáo dục, xóa bỏ rào cản thương mại, thúc đầy mở cửa thị trường, thúc đẩy hoạt động thương mại nông, lâm, thủy sản, tạo điều kiện thúc đẩy thương mại song phương giữa hai nước trong thời gian tới [16].

\subsection{Thảo luận}

Châu Phi được các nước trên thế giới đặc biệt quan tâm trong những năm gần đây bởi các nguyên nhân: Mỹ và các nước phương Tây lo ngại chính phủ một số nước châu Phi bị chủ nghĩa khủng bố lôi kéo và lợi dụng, trở thành nơi hoành hành của chủ nghĩa khủng bố; dân số châu Phi tiếp tục tăng nhanh bất chấp những khủng hoảng trong đời sống xã hội và bệnh dịch, từ đó vai trò kinh tế của châu Phi cũng tăng lên; châu Phi còn là kho tài nguyên vô tận chưa được khai thác triệt để bởi những rào cản trong tiếp cận và hợp tác thương mại...

Trong những năm gần đây, với sự cải thiện không ngừng của quan hệ kinh tế thương mại Việt Nam - châu Phi, không khó để thấy rằng hợp tác chính trị - kinh tế - vắn hóa giữa hai bên ngày càng được cải thiện và nâng cao. Việt Nam đã thiết lập quan hệ ngoại giao với 53 quốc gia ở châu Phi, luôn đánh giá cao nỗ lực chung của các nước châu Phi nhằm xây dựng một cộng đồng khu vực châu Phi đoàn kết và nâng cao vị thế quốc tế. Việt Nam tin tưởng có thể đóng vai trò cầu nối giữa Liên minh châu Phi và ASEAN, vì hòa bình, hợp tác và thịnh vượng của khu vực. Về văn hóa, Việt Nam đã chủ động thành lập trung tâm văn hóa tại Madagascar để tích cực thực hiện các hoạt động giao lưu văn hóa song phương.

Quan hệ kinh tế - thương mại Việt Nam và châu Phi chịu tác động bởi quan hệ quốc tế, Việt Nam luôn tìm kiếm sự ủng hộ về chính trị và an ninh từ các nước châu Phi, đặc biệt sau thời kì 
dịch bệnh cúm gà gây ảnh hưởng không nhỏ tới hợp tác kinh tế song phương. Đồng thời, do giá nguyên liệu tại châu Phi và thế giới giảm đáng kể cũng là một yếu tố quan trọng khiến Việt Nam tiếp tục đẩy mạnh đầu tư sang thị trường châu Phi [15].

Nguyên nhân Việt Nam chưa xây dựng được những chính sách rõ ràng và đầy đủ về hợp tác thương mại với các nước châu Phi còn xuất phát từ ảnh hưởng của một số yếu tố lịch sử, địa lí và chính trị. Cơ cấu các cơ quan ngoại giao và thương mại trong Đại sứ quán Việt Nam tại châu Phi không nhiều, nhân viên Đại sứ quán kiêm nhiệm nhiều chức vụ và là nhà ngoại giao của nhiều nước. Mặc dù cả Việt Nam và các nước châu Phi nói tiếng Pháp đều là thành viên của tổ chức Pháp ngữ, nhưng điều đó chỉ có ý nghĩa với giao lưu văn hóa phi chính phủ giữa hai bên. Động lực thúc đẩy hợp tác thương mại song phương và đầu tư phụ thuộc nhiều hơn vào sự ưu đãi về tài nguyên của đôi bên và những thuận lợi về hợp tác đầu tư trong giai đoạn mới của kinh tế thế giới.

Một số giải pháp có thể thực hiện để thúc đẩy hợp tác kinh tế, thương mại song phương Việt Nam - Châu Phi có tính khả thi đó là: tăng cường hợp tác giữa các Bộ, ngành chức năng, các phòng thương mại và công nghiệp, hiệp hội doanh nghiệp của các bên nhằm thúc đẩy phát triển thương mại hàng nông sản, đảm bảo an ninh lương thực và an ninh năng lượng; tiếp tục hoàn thiện khuôn khổ pháp lý, cơ chế, chính sách nhằm tạo điều kiện cho các hoạt động trao đổi thương mại và hợp tác đầu tư giữa các doanh nghiệp đôi bên; chú trọng công tác thông tin, tuyên truyền, giới thiệu thị trường và đối tác nhập khẩu, tham gia các hoạt động xúc tiến thương mại, hội chợ, triển lãm thường niên... Các doanh nghiệp Việt Nam cần chủ động, tích cực hơn nữa trong việc nắm bắt, cập nhật thông tin, nghiên cứu kỹ về thị trường châu Phi; sử dụng hiệu quả dịch vụ tư vấn thẩm định đối tác, thẩm tra, xác minh trước khi giao dịch, hạn chế rủi ro trong thanh toán; tăng cường gặp gỡ, tiếp xúc trực tiếp và xây dựng chiến lược tiếp cận thị trường phù hợp; nghiên cứu sản xuât sản phẩm xuất khẩu có chất lượng, quy cách, mẫu mã phù hợp với quy định tiêu chuẩn chất lượng, mạng lưới phân phối sản phẩm và tập quán tiêu dùng của thị trường châu Phi; xây dựng và phát triển thương hiệu sản phẩm, duy trì tương quan giữa chất lượng và giá cả hàng hóa; chú trọng đào tạo nguồn nhân lực và nâng cao trình độ khoa học - công nghệ, nâng cao kỹ năng đàm phán, ký kết hợp đồng...

\section{Kết luận}

Châu Phi là thị trường đầy tiềm năng cho các doanh nghiệp xuất khẩu hàng hóa của Việt Nam. Hiện nay, nghiên cứu thị trường Châu Phi để có cách tiểp cận phù hợp là giải pháp tốt cho hợp tác thương mại song phương, giúp Việt Nam mở rộng thị trường mới, tránh phụ thuộc vào một số thị trường truyền thống trước đây. Việc nghiên cứu về quan hệ kinh tế thương mại Việt Nam Châu Phi góp phần đánh giá thực trạng phát triển xuất nhập khẩu hàng hóa của Việt Nam sang thị trường Châu Phi, chỉ ra nguyên nhân của những hạn chế, tôn tại và đề xuất được những giải pháp, chính sách mang tính khả thi là thực sự cần thiết trong bối cảnh mới.

\section{TÀI LIẸU THAM KHẢO/ REFERENCES}

[1] S. Jing Nan, "Xi Jinping discusses running the country: Adhering to the diplomatic philosophy of closeness, sincerity and tolerance," Xinhua News Agency, vol. 1, p. 296, 2018.

[2] C. H. Dinh and T. Q. H. Nguyen, "Situation and Solutions to Export Vietnamese Agricultural Products to the Middle East and Africa Market," Journal for Africa and Middle East Studies, vol. 187, no. 03, pp. 41-42, March 2021.

[3] H. T. Vu, D. D. Tang, "Trade Facilitation and Its Impacts on Vietnam's Trade," in Global Changes and Sustainable Development in Asian Emerging Market Economies, Proceedings of EDESUS, 2019, vol. 1, pp. 513-536.

[4] T. Szigetvári, "Development and Trade Policy in North Africa," in The Post-Crisis Developmental State, Perspectives from the Global Periphery, May 2021, pp. 265-284.

[5] C. A. B. Ha and K. A. Ha, "Online dispute resolution in south africa and some proposes for Vietnam," Journal for Africa and Middle East Studies, vol. 179, no. 01, p. 31, July 2020.

[6] C. Trinh, "Africa in the strategy of big countries," Communist Review, no. 07, pp. 74-76, April 2006. 
[7] Vietnam People's Army online, "Vietnam's exports to Africa reached nearly 3 billion USD in 2018," (in Chinese), January 20, 2019. [Online]. Available: http://cn.qdnd.vn/cid-6158/7193/nid-557007.html. [Accessed October 20, 2021].

[8] T. H. Nguyen, "Egypt's look East polocy and Vietnam-Egypt cooperation opportunities," Journal for Africa and Middle East Studies, vol. 163, no. 03, p. 39, March 2019.

[9] Vietnam News Agency online, "President Tran Dai Quang's trip to Ethiopia and Egypt: deepening the traditional friendship between Vietnam and African countries," (in Chinese), August 22, 2018. [Online]. Available: zh.vietnamplus.vn/84693.vnp. [Accessed October 20, 2021].

[10] Vietnam News Agency online, "The prospect of trade and investment cooperation between Vietnam and African countries is still wide," (in Chinese), August 24, 2018. [Online]. Available: zh.vietnamplus.vn/84767.vnp. [Accessed October 20, 2021].

[11] The Central Organ of the Communist party of Vietnam online, "Vietnam occupies a central position in Egypt's "Look East" policy," (in Chinese), March 20, 2019. [Online]. Available: https://cn.nhandan.vn/theodong/item/6862201.html. [Accessed October 20, 2021].

[12] Vietnam Business Forum, "Enhancing the sustainable cooperation relationship between Vietnam and Africa," August 25, 2010. [Online]. Available: https://vccinews.vn/news/1679/.html. [Accessed October 20, 2021].

[13] Vietnam Pictorial online, "Vietnam wishes to promote cooperation with African countries," (in Chinese), April 25, 2019. [Online]. Available: https://vietnam.vnanet.vn/chinese/430036.html. [Accessed October 20, 2021].

[14] Vietnam News Agency online, "Vietnamese Prime Minister Nguyen Xuan Phuc receives Minister of Foreign Affairs and Cooperation Botswana," (in Chinese), August 26, 2019. [Online]. Available: https://zh.vietnamplus.vn/101340.vnp. [Accessed October 20, 2021].

[15] Vietnam News Agency online, "Strengthening economic cooperation between Vietnam and African countries," (in Chinese), November 5, 2019. [Online]. Available: https://zh.vietnamplus.vn/104371.vnp. [Accessed October 20, 2021].

[16] Vietnam News Agency online, "Pham Minh Chinh - Politburo member of the Central Committee of the Communist Party of Vietnam visited and worked in Egypt," (in Chinese), December 13, 2019. [Online]. Available: https://zh.vietnamplus.vn/106181.vnp. [Accessed October 20, 2021].

[17] Vietnam News Agency online, "Africa is still a market with great potential in the post-pandemic period," (in Chinese), July 10, 2020. [Online]. Available: https://zh.vietnamplus.vn/119865.vnp. [Accessed October 20, 2021]. 